\title{
Evaluating E-Learning Systems: An Empirical Investigation on Students' Perception in Higher Education Area
}

\author{
http://dx.doi.org/10.3991/ijet.v9i4.3480 \\ M.M. Abbad ${ }^{1}$ and F.N. Jaber ${ }^{2}$ \\ ${ }^{1}$ Hashemite University, Zarqa, Jordan \\ 2 Arab Open University, Amman, Jordan
}

\begin{abstract}
In search of better, traditional learning universities have expanded their ways to deliver knowledge and integrate cost effective e-learning systems. Universities' use of information and communication technologies has grown tremendously over the last decade. To ensure efficient use of the e-learning system, the Arab Open University (AOU) in Bahrain was the first to use e-learning system there, aimed to evaluate the good and bad practices, detect errors and determine areas for further improvements in usage. This study critically evaluated the students' perception of the elearning system in Bahrain and recommended changes to improve students' e-learning usage. Results of the study indicated that, in general, students have favourable perceptions toward using the e-learning system. This study has shown that technology acceptance is the most variable, factor that contributes to students' perception and satisfaction of the e-learning system.
\end{abstract}

Index Terms-e-learning, IT success, online learning, students' satisfaction, technology acceptance, usefulness.

\section{INTRODUCTION}

This paper investigates the effectiveness of information technology (IT) applications adopted by teaching organisations, and will help in building a perspective on technology management. Since the role of marketing is to create a consistency between the product offering and its appropriate customer perception, organisations must dynamically adapt to the changing customer perception of IT application over time [1]. Introducing a new technology can be an overwhelming experience for organisations, especially considering the lack of case studies and benchmarks available [2]. Over the last two decades universities have used the multimedia technology and the internet to improve the quality of learning, and to ensure success in marketing e-learning system at universities. This research conducts a comparative case of an e-learning system, helping to gain an appreciation of how the internet supports the learning process of the students.

As the world moves online, technological developments increase the pressure on face-to-face learning to move towards online learning. According to [3], pressures on industry and organisations are from the market, technology, and society. Market pressures include global competition and consumers. Technological pressures include the use of e-commerce to lower the cost. Social pressures include skills gap, demographic changes, and demand for flexible access of lifelong learning.
According to [4], e-learning is training delivered on a computer (including Internet, conference, $\mathrm{CD}$, or intranet); it is designed to enhance knowledge, individual learning and organisational performance goals. This research was based at AOU in Bahrain, which uses low cost and high performance information communication technology (ICT). AOU in Bahrain is a leading university that started on August 2002 and was the first to use the e-learning system there. AOU adopted an open learning approach and utilised modern IT resources to support the learning process. Moreover, it built a partnership with the United Kingdom's Open University (UKOU) and UNISCO. AOU's e-learning system is based on its customised learning management system (LMS) platform called (AOULMS).

The rapid growth and integration of e-learning programs has prompted educational organisations and researchers to question what perception students have toward e-learning, so as to find ways to improve acceptance. This research aims to evaluate and identify students' perceptions of the current e-learning system values at AOU, and determine the impact of perceptions of e-learning on constructing their learning knowledge.

The results of the research tend to develop further opportunities and sustainable competitive advantages to AOU by understanding the students' perception on the elearning system to increase the efficiency of the system.

First, the literature on students' perception and experience of e-learning systems is reviewed. This review gives implications for the present study. Then the methodology used to collect and analyse data in the study is presented. After that the results are outlined and their theoretical implications are discussed. Finally, conclusions and discussion of the study are presented.

\section{LITERATURE REVIEW}

The rapid growth and integration of e-learning programs has prompted universities and researchers to question and examine the students' perception of e-learning system. This is understandable in view of the importance of students' perception to the success of the e-learning system. Researches have examined several factors or variables, which affect the students' perception and experience toward the e-learning system. In this study the factors that affect students' perception on an e-learning system will be reviewed. These factors vary to include: discipline, motivation, individual differences, technology experience, flexibility, instructor role, course management 
PAPER

Evaluating E-LEARning Systems: An EMPIRICAL INVESTIGATION ON STUdENTS’ PERCEPTION IN HiGHER...

issues, implementation strategy, demographics variables, technical support, and technology acceptance, as suggested by the literature.

Many studies have shown that students in the online environment need a significant discipline and motivation to complete their learning process [5]. This is specifically true, where students are independent in completing their course (self-study), as opposed to students in the traditional classroom environment that interact with the community. However, [5] have proved that completing online course needs significant time investment from the student.

In addition [5] stated that e-learning students' performance during the learning process is affected by their self motivation. It also shown that the most important factor, which affects students' motivation, is the students' interest in the course content and their perceived value of the course. The more students see the perceived value of the course, the more they will be motivated to learn [5]. Individual differences emerge as a possible contributor to students' perception [6]. Research indicated that the way students construct their knowledge during the learning process has impact on their study strategies and perception of e-learning [7]. They also indicated that it is not enough to hope for a match between the students' conception of the learning process and the instructor's intention; there is a need of clear explanation to students of the goals of the e-learning system and the expectation of activities they will undertake.

Research has shown the emotion of the students' experience and a concern about time and time management as critical factors affecting students' perception [7]. Furthermore, as students become more experienced in online instruction, their attitudes toward the e-learning system may change [5]. Researchers stated that, the more online courses taken, the more satisfaction with the e-learning system; and, the more technical problems the students face, the less encouragement and satisfaction they had towards the e-learning system [8,9]. In contrast [10] argued, students with technology experience may not necessarily appreciate the e-learning system, and students without this experience may appreciate it more. Consequently the student's technology experience may not be a significant factor contributing to students' satisfaction in all contexts.

Flexibility is a major factor that has a significant impact on students' perception on e-learning. Students sign up for the e-learning system for its flexibility [8,11]. Flexibility does not mean no deadline, but the usage of overlapping availability and deadline for quizzes (i.e. test one is available from week 1 to 4 , and test two is available from week 3 to 6$)$.

Researchers stated that it is wrong to ignore the instructor's role in the students' satisfaction of e-learning, because the students' satisfaction is related more to the instructors and instructions than technology $[8,11]$. Interaction and contact with the instructor is found as a primary factor affecting students' satisfaction [8]. It is the instructor's responsibility to translate the instruction to adapt the e-learning method.

"Ref. [8]" also mentioned other instructor related factors, which affect students' satisfaction. These include timely feedback from the instructor and interaction with the instructor. Instructors should give feedback to students' assignments and practices. This response is rec- ommended to be within 24 hours. Instructors may need to set office hours of availability to enable more interaction with students. These feedbacks are recommended to be meaningful, semi-formal, and personalised, to include personal comments and use of the student's name.

The management of the learning process must be handled with sensitivity and considerable skills to impact positively on students' perception $[12,13]$. Course management issues are found to be significant factors affecting students' perception of e-learning system. These include clarity and relevant real-world assignments, access to campus resources, technical support, orientation, technology, and course content quality. Several studies have indicated that students use the e-learning system to manage solving their assignments. Therefore the assignment tool has the strongest positive feedback towards the elearning system $[14,15]$. "Ref. [8]" have shown that students' ability to print online material is an interesting factor, which affects students' perception of e-learning system. According to [12], in the e-learning discussions and chat when knowledge is shared for a public good, then students participate and share the knowledge motivated by moral and community interest. But when knowledge is shared for private good, students are more reluctant to share and act out of self-interest rather than social responsibility.

Research has indicated that the strategy of implementing the e-learning system at the university potentially affects students' perception more than students' individual background variables, which include age, gender, technology experience, technology acceptance, and individual learning style [10].

"Ref. [10]" stated that although, male students are supposed to use technology more than females, female students in their research were more positive than male students towards the e-learning system, and age does not have any impact on students' perception of e-learning system. They explained the main reason for those findings is that female and male students have different expectations and intentions to use. Male students use the elearning system for its usefulness, but female students use the e-learning system for its ease of use. However, [5] mentioned that there are no significant differences for students' perception if the gender changed.

E-learning is a technology introduced to students. The students' technology acceptance should have an impact on their perception $[16,17]$. One of the primary technology acceptance theories is Roger's [18] framework of technology acceptance within the theory of diffusion and innovations. This theory includes five adopter categories, which are innovator, early adopter, early majority, late majority, and laggards. Although the early adopter and innovator students are supposed to have a positive impact of the elearning system as a new technology, [10] indicated, early adopters and innovators students did not have a positive perception of the e-learning system.

Another important technology acceptance theory is technology acceptance model (TAM), introduced by Davis [19]. TAM is an adaptation of theory of reasoned action (TRA) specifically tailored for modelling user acceptance of information system. TAM posits that two particular beliefs perceived usefulness and perceived ease of use are of the primary relevance for computer acceptance behaviours. 
PAPER

Evaluating E-LEARning Systems: An EMPIRICAL INVESTIGATION ON STUdENTS’ PERCEPTION IN HighER...

"Ref. [20]" defined the technical support as, "Knowledge people assisting the uses of computer hardware and software products". Technical support is an important factor that affects the students' satisfaction and acceptance of the technology for teaching [21]. The high level of organisational support, including management support and information centre support, is important to promote favourable attitudes regarding the e-learning system [22]. Technical support is essential for achieving significant success in applying information technology in learning, and it is important in the beginning stage of the technology adoption. "Ref. [23] found that the critical success factors within a university environment include university support.

\section{Methodology}

Because of the quantitative and qualitative nature of the research objectives, mixed approaches are adopted for the purpose of achieving the research objectives. Firstly, to evaluate and identify the factors that influence students' perception of AOU-LMS system the qualitative approach was conducted using focus-group interviews. Secondly, to explore the relative importance of the identified factors, and evaluate the good and bad practices, a quantitative phase was conducted using questionnaire survey. The combination of methods supported credibility in findings through triangulation of the data. The basic assumption of triangulation is the weaknesses in each single data collection method are compensated by the counterbalancing strengths of another method [24].

In consideration of these points of view and in particular to enhance the depth of the research findings, this research conducted three semi-structured recorded sessions with three to five students. Each session focused on understanding students' views, interests, opinions, attitudes, perspectives, and assumptions that affect students' perceptions.

A survey was conducted at the AOU in Bahrain using a structured self-administered questionnaire. The main aim of the questionnaire was to determine how the students perceive the value of the AOU-LMS, and how they described the experience of working with such a system. The questionnaire included questions about students' demographics, students' technology experience and usage of the e-learning system, satisfaction with e-learning system tools, and a set of statements designed to measure students' perceptions toward the e-learning system.

The questionnaires included (yes-no), multiple choice, and scale questions. In some of the questions (openended) a space was provided for students to answer the question. Since Arabic is the main language spoken in Bahrain, the questionnaire's Arabic version was developed and translated from an initial English version.

\section{A. Sample}

A better insight into students' perception was built by conducting focus group sessions, which established an items pool for the questionnaire development. The focus group method has been employed at the initial phase of the research due to its ability to achieve research goals within the available resources [25]. Determining the number of focus groups is essential to be determined at the initial phase of this research. The most common rule of thumb is that most projects consist of three to six group sessions [26]. In the light of the questionnaire goals and available resources, a decision was made to run three focus group sessions. The small number of participants in the focus group sessions increases the interaction among participants [25]. However, group size can range from as few as four to as many as twelve [27]. For the purpose of this research and due to the time limitation, as the interviewer conducted interviews during class break, a decision was made to recruit four participants in each interview. This research is sensitive to the demographic variables and recruited participants from different gender, age, and schools to show different perspectives.

The interviews were conducted at the Arab Open University (AOU) in Bahrain. AOU has one main branch in the biggest city in Bahrain, namely Manamah (capital). Participants in the study consisted of undergraduate students who were taking the last lecture of the first basic computer literacy course called GR100 for students who are studying at the Business School and TU170 for students who are studying at the IT School.

In this research participation to the questionnaire was optional, as 58 of 63 students, students who were enrolled in these classes agreed to take part, which means $(92 \%)$ of the students participated and filled the questionnaire. Participants in the study consisted of undergraduate students who were taking the last lecture of the first basic computer literacy classes called GR100 and TU170 at Arab Open University (AOU) in Bahrain. Three questionnaires were later identified and deleted due to excessive item nonresponse. Thus, 55 questionnaires were included in the analysis.

The low level of university facility usage is a result of the previous findings in this section, which show that most participants are young, full time workers, and have Internet connection at home and Internet experience. Consequently they are too busy to come to the university campus, and they have the facility and technology experience enabling them to use the e-learning system at home at their own schedule.

\section{DATA ANALYSIS}

\section{A. Focus group analysis}

Based on an extensive review of the literature, the main issues that needed to be explored during the focus group session were identified. Thus, the main subjects that needed to be explored depending on students' perception and perspective are: motivation, individual differences, technology experience, flexibility, Instructor role, technical support, and technology acceptance.

\section{1) Motivation}

Motivation is the reasons for the students to use the elearning system. Some studies have shown that students need a significant discipline and motivation to complete their learning process using the e-learning system [5]. In the interviews, participants' responses about the reasons behind their usage of the e-learning system indicated that there is more than one motivation. These motivations vary to include: to increase their knowledge, flexibility of the learning, and encouragement from the instructor.

This list of motivations represents different opinions and situations that are compatible with the findings of previous studies in this area [5,8]. Furthermore, a careful analysis of participants' answers in the interviews indicated an important role of students' motivation in the way the 
PAPER

Evaluating E-LEARNING Systems: An EMPIRICAL INVESTIGATION ON STUDENTS’ PERCEPTION IN HigHER...

students respond to their experience with the e-learning system.

\section{2) Individual differences}

The individual differences appear as a possible contributor to students' perception. It was found from the focus group interviews that there are individual differences regarding students' study strategies and preferred elearning tools. Students represent different experience and perception based on different individual differences variables including style, job, emotions, and technology experience. The main thing that most of the students agreed on regardless of the individual differences, is that e-learning enhances and complements the face-to-face learning.

\section{3) Technology experience}

The literature review has shown that the technology experience variable has significant positive or negative impact on students' perception [7]. It was recognised in the interviews that students have similar high technology experience with Internet and browsing, which makes it easy for them to use the e-learning system.

From the interviews, agreement seems to exist among students about the good technology experience they have. On the other hand, there is a lack of agreement about the satisfaction with the e-learning system. As mentioned in the literature review technology experience does not necessary lead to satisfaction with the e-learning system. Furthermore, as students become more experienced in online instruction, their attitudes toward the e-learning system may change [5]. More precise analysis that links the technology experience with the students' perception on e-learning system is conducted in the questionnaire analysis.

\section{4) Flexibility}

The literature review has mentioned flexibility as a major factor that has a significant impact on students' perception of e-learning, as they sign up for the e-learning system for its flexibility [8]. In the interviews, agreement seems to exist among students about their need for such an e-learning system because of the flexibility it offers. Students explained their answers and mentioned that LMS should support and not fully replace the traditional lecture; they liked having blended learning. Flexibility was mentioned earlier in this section as a motivation for the students to use the LMS system.

\section{5) Instructor role}

The literature review suggested that students' satisfaction is related more to the *instructors and instructions than technology [8]. In the interviews with the students, some of them have commented that they use the elearning discussion forums because the instructor motivated them to do so.

\section{6) Technical support}

Technical support has been defined as an important factor affecting students' perception on e-learning as mentioned in the literature review [21]. In the interviews it was noticed that students have good impact regarding the technical support, which could have a positive impact toward the e-learning system.

\section{7) Technology acceptance}

The students' technology acceptance should have an impact on their perception towards the e-learning system [28]. An important technology acceptance theory is the technology acceptance model (TAM), introduced by [19]. TAM posits that two particular beliefs perceived usefulness and perceived ease of use are of the primary relevance for computer acceptance behaviours.

To highlight the usefulness factor of the TAM model, students were asked about the effectiveness of the elearning. Most of them had similar attitudes and answered that the e-learning system is useful and an effective way to construct their knowledge. In addition, to highlight the 'ease of use' factor of the TAM model, students were asked about the easiness of the e-learning system by asking them to evaluate the LMS accessibility, interface, navigation, and design. Most students responded that the system is easy to use.

\section{B. Questionnaire Data Analysis}

In this study, software called the Statistical Package for Social Science (SPSS) was used to analyse the questionnaire, to examine relationships between variables or the difference between groups/conditions. In the results, the researcher tried to find some relations between questions as well as presenting statistical information including tables and figures for these questions.

1) The impact of demographic variables on the students' perception

A series of analysis of variances (ANOVAs) has been used to determine demographic variables (gender, age, income, and internet experience) differences on the factors or variables contributing to the students' perception of the e-learning system (flexibility FX, technical support TS, individual differences ID,

Gender, age, income and internet experience effects upon FX, TS, ID, TA, MT, and IR have been examined using ANOVA. The mean scores, standard deviation, $F$ ratios, and significant of $F$ ratios for each demographics variable are shown sequentially in Tables 1, 2, 3, and 4 .

As shown in Table 1, male students have higher mean score than female students on all factors. Using a significance of 0.10 , there are significant gender differences on the flexibility factor that affects students' perception of elearning system. This indicates that men perceive the flexibility benefit of the e-learning system more than female.

As shown in Table 2, the mean scores for students' age category between 20 and 30 years are lower than other age categories' mean scores. Using a significance of 0.10 , there are no significant age differences on the six factors. Moreover, looking at Table 3 there are no significant income differences on the six factors.

Regarding the Internet experience, most students have more than three years of internet experience. Looking at Table 4 and using the significance of 0.10 , there are significant internet experience differences on the motivation factor that affect students' perception. This indicates that students who have less than one year Internet experience are more motivated to use the LMS system than students with more than two years' experience. 
PAPER

Evaluating E-LEARning Systems: An EMPIRICAL INVESTIGATION ON STUDENTS’ PercePtion In HigheR...

TABLE I.

GENDER DESCRIPTIVE STATISTICS AND ANOVAS TESTING RESULTS

\begin{tabular}{|c|c|c|c|c|c|c|}
\hline \multirow{2}{*}{ Factor } & \multicolumn{2}{|c|}{ Female $(n=27)$} & \multicolumn{2}{|c|}{ Male $(n=28)$} & \multicolumn{2}{|c|}{ F Test } \\
\hline & Mean & $S D$ & Mean & $S D$ & F Ratio & F Sig. \\
\hline Flexibility & 3.61 & 0.78 & 3.98 & 0.75 & 3.19 & $0.080 *$ \\
\hline Technical support & 3.65 & 0.66 & 3.85 & 0.49 & 1.60 & 0.210 \\
\hline Individual differences & 3.70 & 0.78 & 3.91 & 0.59 & 1.21 & 0.275 \\
\hline Technology acceptance & 3.64 & 0.60 & 3.97 & 0.67 & 3.52 & 0.066 \\
\hline Motivation & 3.58 & 0.58 & 3.80 & 0.73 & 1.41 & 0.239 \\
\hline Instructor role & 3.40 & 0.96 & 3.55 & 1.02 & 0.31 & 0.578 \\
\hline
\end{tabular}

TABLE II.

AGE DESCRIPTIVE STATISTICS AND ANOVAS TESTING RESULTS

\begin{tabular}{|c|c|c|c|c|c|c|c|c|c|c|}
\hline \multirow[t]{2}{*}{ Factor } & \multicolumn{2}{|c|}{$\begin{array}{c}\text { Less than } 20 \text { years } \\
(n=3)\end{array}$} & \multicolumn{2}{|c|}{$\begin{array}{c}\text { Between 20-30 years } \\
(n=42)\end{array}$} & \multicolumn{2}{|c|}{$\begin{array}{c}\text { Between 30-40 years } \\
(n=7)\end{array}$} & \multicolumn{2}{|c|}{ More than 40 years } & \multicolumn{2}{|c|}{ F Test } \\
\hline & Mean & $S D$ & Mean & $S D$ & Mean & $S D$ & Mean & $S D$ & F Ratio & F Sig. \\
\hline FX & 4.50 & 0.50 & 3.76 & 0.83 & 3.64 & 0.47 & 4.00 & 0.86 & 0.98 & 0.407 \\
\hline TS & 4.00 & 0.90 & 3.76 & 0.55 & 3.57 & 0.77 & 3.83 & 0.28 & 0.41 & 0.745 \\
\hline ID & 4.16 & 1.04 & 3.77 & 0.73 & 3.64 & 0.37 & 4.33 & 0.28 & 0.99 & 0.402 \\
\hline TA & 4.33 & 0.76 & 3.77 & 0.67 & 3.75 & 0.64 & 4.00 & 0.25 & 0.77 & 0.516 \\
\hline MT & 4.13 & 1.17 & 3.68 & 0.66 & 3.54 & 0.67 & 3.73 & 0.30 & 0.53 & 0.659 \\
\hline IR & 3.33 & 1.52 & 3.46 & 0.98 & 3.42 & 0.83 & 4.00 & 0.50 & 0.31 & 0.816 \\
\hline
\end{tabular}

TABLE III.

INCOME DESCRIPTIVE STATISTICS AND ANOVAS TESTING RESULTS

\begin{tabular}{|c|c|c|c|c|c|c|c|c|c|c|}
\hline \multirow[t]{2}{*}{ Factor } & \multicolumn{2}{|c|}{$\begin{array}{c}\text { Less than } 200 \text { BD } \\
(n=7)\end{array}$} & \multicolumn{2}{|c|}{$\begin{array}{c}\text { Between 200-500 BD } \\
(n=17)\end{array}$} & \multicolumn{2}{|c|}{$\begin{array}{c}\text { Between 500-800 BD } \\
(n=15)\end{array}$} & \multicolumn{2}{|c|}{$\begin{array}{c}\text { More than } 800 \text { BD } \\
(n=16)\end{array}$} & \multicolumn{2}{|c|}{ F Test } \\
\hline & Mean & $S D$ & Mean & $S D$ & Mean & $S D$ & Mean & $S D$ & F Ratio & F Sig. \\
\hline FX & 3.93 & 0.78 & 3.85 & 0.78 & 3.53 & 0.83 & 2.93 & 0.75 & 0.82 & 0.489 \\
\hline TS & 3.82 & 0.74 & 3.82 & 0.49 & 3.51 & 0.56 & 3.89 & 0.61 & 1.23 & 0.308 \\
\hline ID & 4.21 & 0.69 & 3.61 & 0.69 & 3.73 & 0.67 & 3.90 & 0.68 & 1.41 & 0.251 \\
\hline TA & 3.89 & 0.70 & 3.72 & 0.45 & 3.68 & 0.68 & 4.00 & 0.70 & 0.76 & 0.519 \\
\hline MT & 4.00 & 0.66 & 3.68 & 0.51 & 3.58 & 0.72 & 3.67 & 0.78 & 0.60 & 0.616 \\
\hline IR & 3.57 & 0.73 & 3.50 & 0.73 & 3.69 & 1.02 & 3.31 & 1.23 & 0.25 & 0.860 \\
\hline
\end{tabular}

TABLE IV

INTERNET EXPERIENCE DESCRIPTIVE STATISTICS AND ANOVAS TESTING RESULTS

\begin{tabular}{|c|c|c|c|c|c|c|c|c|}
\hline \multirow{2}{*}{ Factor } & \multicolumn{2}{|c|}{ Never $(n=1)$} & \multicolumn{2}{|c|}{ Less than 1 year $(n=2)$} & \multicolumn{2}{|c|}{ More than 2 years $(n=52)$} & \multicolumn{2}{|c|}{ F Test } \\
\hline & Mean & $S D$ & Mean & $S D$ & Mean & $S D$ & F Ratio & F Sig. \\
\hline FX & 3.50 & - & 4.75 & 0.35 & 3.76 & 0.78 & 1.61 & 0.209 \\
\hline TS & 3.25 & - & 4.12 & 0.53 & 3.75 & 0.59 & 0.75 & 0.473 \\
\hline ID & 3.00 & - & 4.25 & 1.06 & 3.89 & 0.68 & 1.07 & 0.348 \\
\hline TA & 3.50 & - & 4.25 & 1.06 & 3.81 & 0.65 & 0.55 & 0.578 \\
\hline MT & 3.00 & - & 4.60 & 0.56 & 3.67 & 0.65 & 2.50 & $0.091 *$ \\
\hline IR & 4.00 & - & 4.25 & 1.06 & 3.44 & 0.96 & 0.82 & 0.446 \\
\hline
\end{tabular}

\section{2) E-learning tools evaluation analysis}

This section analyses empirical data that were used to determine the e-learning tools the students valued and preferred. The questionnaire participants were asked to rate the elements of LMS according to how they have enhanced their learning process. The main aim of this question was to determine how the students perceive the value of the e-learning tools. Table 5 displays the elearning tools or elements, the overall means and standard deviations of the students' evaluation.

The scale of e-learning tools' evaluation range from highly beneficial (5) to not used (1). In Table 5, e-learning tools means ranged from 4.20 to 2.74 , indicating highly beneficial to limited benefits. The top three tools that the students seemed to valued from highest to lowest are assignment (mean 4.2; SD 0.98), resources (mean 4.14; SD 0.98), and announcements (mean, 4.00; SD 0.96). Students seemed to perceive a limited value from the video podcasts (mean 3.18; SD 1.34), and chat tool (mean 2.74; mean; SD 1.37).

As displayed in Table 5, students valued the assignments tool more than other e-learning tools. The standard deviation of the assignments tool is low and its mean is high. This indicates the high level of agreement that exists between students on the high benefits of the assignment tool, which helped students to construct their knowledge. This is reasonable because the assignments at AOU have $50 \%$ of each course mark. In addition, students need to study and read the course contents in order to do their assignments that will increase their in-depth knowledge.

Students see limited benefits from the chat tool. This might be because the chatting rooms are facing lack of participants and there is no motivation from the instructors to direct students to chat with each other. In addition, students are afraid to say something silly or the chat tool is facing technical problems. Also, students do not see high benefits come from the audio and video tool. This might 
be because not all instructors use this tool to deliver the course materials.

\section{3) Students' perception of e-learning}

Attitudes toward perceptions of e-learning system were measured using 19 likert-type statements to which respondents were required to state their level of agreement or disagreement. A 5-point category response format was employed with the following category labels: $1=$ strongly disagree, $2=$ disagree, $3=$ neither disagree nor agree (normal), $4=$ agree, and $5=$ strongly agree. The statements were developed based on the literature review, and from the focus group discussions with students at AOU in Bahrain. From the literature review and from the focus group discussions, it was clear that the main variables contributed to the students' perception of e-learning are flexibility (FX), technical support (TS), individual differences (ID), technology acceptance (TA), motivation
(MT), and instructor role (IR). Thus statements were framed to reflect these variables impact on students' perception. The relevant statements are shown in Table 6 .

Then each respondent's scores on all statements were summed to obtain the mean that represents the level of students' perception, as displayed in Table 7, measured by the FX, TS, ID, TA, MT, and IR.

Next, respondents were ranked according to their total means. Table 8 shows mean and standard deviation of responses to the 19 students' perception statements used in the final analysis. All mean scores are above the scale mid-point of three, and the standard deviation values indicate high level of agreement between students. It has been observed that TA has the highest mean score and the lowest standard deviation. It is the most variable that contributes to students' satisfaction with the e-learning system.

TABLE V.

E-LEARNING TOOLS MEANS AND STANDARD DEVIATION

\begin{tabular}{|c|c|c|}
\hline E-learning Tool & Mean & Standard deviation (SD) \\
\hline Assignment & 4.20 & 0.98 \\
\hline Resources & 4.14 & 0.82 \\
\hline Announcements & 4.12 & 0.96 \\
\hline Past exam papers & 4.00 & 1.21 \\
\hline Forums & 3.90 & 1.08 \\
\hline Assessments & 3.70 & 1.10 \\
\hline External web links & 3.69 & 1.06 \\
\hline E-mail & 3.67 & 1.17 \\
\hline Library or IT facilities & 3.50 & 1.31 \\
\hline Chat & 3.18 & 1.34 \\
\hline
\end{tabular}

TABLE VI.

STATEMENTS REFLECT FACTORS IMPACT ON STUDENTS' PERCEPTION

\begin{tabular}{|c|c|c|c|}
\hline Factor (variable) & Statement & Mean & SD \\
\hline \multirow{2}{*}{ Flexibility } & LMS provides a flexible way to learn & 4.10 & 0.76 \\
\hline & The LMS provides useful links to other web-based learning resources & 3.49 & 1.16 \\
\hline \multirow{4}{*}{ Technical Support } & I received sufficient training in the use of the $L M S$ system & 3.38 & 0.97 \\
\hline & I don't have difficulty accessing the LMS & 4.18 & 0.79 \\
\hline & LMS modules are usually updated on weekly basis & 3.65 & 1.07 \\
\hline & The LMS facilitates group solve technical problems efficiently & 3.81 & 4.14 \\
\hline \multirow{2}{*}{$\begin{array}{l}\text { Individual differ- } \\
\text { ences }\end{array}$} & E-learning complements the face-to-face Learning & 4.14 & 0.65 \\
\hline & I think e-learning can replace traditional learning & 3.47 & 1.13 \\
\hline \multirow{4}{*}{$\begin{array}{l}\text { Technology } \\
\text { Acceptance }\end{array}$} & Navigation through the LMS is easy & 4.16 & 0.85 \\
\hline & Using LMS has enhanced the knowledge and understanding I gain from practices & 3.63 & 0.98 \\
\hline & The LMS allows me to provide feedback to my lecturers and teachers & 3.50 & 1.05 \\
\hline & $\begin{array}{c}\text { The LMS is a useful one-stop resource that includes information I might need for my studies, such as } \\
\text { textbooks, Related Articles and papers, reading lists, and access to teachers }\end{array}$ & 3.94 & 0.91 \\
\hline \multirow{5}{*}{ Motivation } & The (LMS)'s discussion forums are a useful way of building my knowledge & 3.74 & 0.98 \\
\hline & Tests posted on the LMS are useful way to check my course understanding & 3.81 & 1.03 \\
\hline & I use LMS to download or view PowerPoint presentations and lecture notes & 4.12 & 0.84 \\
\hline & I think LMS resources tool has mostly enhanced my learning process & 3.69 & 0.97 \\
\hline & I think library has mostly enhanced my learning process & 3.09 & 1.26 \\
\hline \multirow{2}{*}{ Instructor's role } & I think LMS discussion forums tool has mostly enhanced my learning process & 3.54 & 0.97 \\
\hline & I think LMS practices and tests tool has mostly enhanced my learning process & 3.41 & 1.04 \\
\hline
\end{tabular}


PAPER

Evaluating E-LEARning Systems: An EMPIRICAL INVESTIGATION ON STUdENTS’ PERCEPTION IN HigheR...

TABLE VII.

FACTORS’ MEANS THAT REPRESENT STUDENT’S PERCEPTION OF E-LEARNING

\begin{tabular}{|l|c|c|}
\hline Factor (variable) & Mean & Standard Deviation (SD) \\
\hline Flexibility & 3.80 & 0.78 \\
\hline Technical Support & 3.75 & 0.58 \\
\hline Individual differences & 3.80 & 0.69 \\
\hline Technology Acceptance & 3.81 & 0.65 \\
\hline Motivation & 3.69 & 0.67 \\
\hline Instructor's role & 3.48 & 0.96 \\
\hline
\end{tabular}

TABLE VIII.

FACTORS' MEANS THAT REPRESENT STUDENT'S PERCEPTION ON E-LEARNING RANKED ACCORDING TO THE MEAN

\begin{tabular}{|l|c|c|}
\hline actor (variable) & Mean & Standard Deviation (SD) \\
\hline Technology Acceptance & 3.81 & 0.65 \\
\hline Individual differences & 3.80 & 0.69 \\
\hline Flexibility & 3.80 & 0.78 \\
\hline Technical Support & 3.75 & 0.58 \\
\hline Motivation & 3.69 & 0.67 \\
\hline Instructor's role & 3.48 & 0.96 \\
\hline
\end{tabular}

\section{4) Data analysis conclusion}

The results have identified (AOU)'s students' perception of the current e-learning system values, determined and explored the relative importance of different factors that affect the student's perception of e-learning in Bahrain, and identified the relationship between the demographic variables and the students' perception of elearning.

The data were analysed using the SPSS program and it was found that students valued the assignments tool more than other e-learning tools. This finding is consistent with past studies, which have indicated that the assignment tool has the strongest positive feedback towards the e-learning system $[14,15]$. Also, students seemed to see limited benefits come from the chat tool in the e-learning system. Therefore, this research provides support for authors such as [12], who have posited that managing e-learning courses must be handled with sensitivity to impact positively on students' perception towards e-learning tools, especially for the chat tool and failing to do so will lead to negative feedback towards the chat tool.

A series of analysis of variances (ANOVAs) has been used to determine demographic (gender, age, income, and internet experience) difference on the factors or variables contributing to the students' perception of the e-learning system. It was found that there is a significant gender difference on the flexibility factor that affects students' perception on e-learning system, as men perceive the flexibility benefit of the e-learning system more than female, and male students have more positive feedback than female students. This is contrary to the findings of [5], who indicated in their research that female students were more positive than male students towards the elearning system.

Also, there are no significant age or income differences on the factors that affect the students' perception. In addition, there is a significant Internet experience difference on the motivation factor and students with less experience are more motivated to use the e-learning system. This conclusion appears to support [10] findings that students with technology experience may not necessary appreciate the e-learning system.

\section{IMPLICATIONS AND CONTRIBUTIONS}

This research contains a wide ranging and detailed study of students' perception of the e-learning system at AOU in Bahrain. The contribution to knowledge relates particularly to open universities in general and AOU in specific and the following paragraphs describe the three major areas in which this contribution has been made. It also, contributes to the e-learning literature by providing insights on the variables or factors that seem to affect students' perception. University administrators and designers would like to be able to predict whether the system will be acceptable to students, diagnose the reasons why the system may not be fully acceptable to students, and to take corrective action to increase the acceptability of the system. This study suggests that university administrators, designers, and instructors should stress the variables discussed in this research. A large number of studies have been conducted in developed countries, and the need to conduct research in the context of developing countries is obvious.

Based on an extensive review of the literature and focus group discussions, it was concluded that the main variables that contribute to students' perception of e-learning are: flexibility [8], technical support [29], individual differences [7], technology acceptance [19], motivation [5], and instructor role [8].

E-learning tools were evaluated and the results showed that the students valued the assignment tool more than other e-learning tools. In addition, they see limited benefits from the chat tool. Moreover they valued the audio and video tool less than other e-learning tools.

Finally, this study can be very beneficial to many educators such as policy makers because variables in the 
study can help to predict and evaluate students' perception of e-learning system. It can also be important for administrators and instructors to understand how to determine constructs of students' perception of e-learning system because it can speed up the rate of adoption. The work has some considerable originating in both using focus group interviews and conducting the analysis in the context of a developing country rather than a developed one (as the case with most studies).

This study expands the knowledge of the students' perception of e-learning systems. However, it is thought that there are some limitations of this research because it doesn't reflect the variety of attitude that may exist in different countries and it was primarily limited to 55 students in Bahrain who are studying at AOU.

The current study provides numerous opportunities for further research because technology acceptance is the most influential factor upon students' perception of the elearning system. University administrators need to carefully design the system to make it as easy as possible, useful, and give the students training courses on how to use the system to increase the students' attitude to use the system. In addition, instructors' perception of the e-learning system needs to be investigated since the instructors are the other user of the system. Moreover, future research should explore other variables that may have an effect on students' perception of e-learning systems, such as cost of the Internet connection, availability of the system, students' background, and students' GPA.

\section{REFERENCES}

[1] D. Adcock and C. Ross (2001) "Marketing Principles and Practice: 4th edition". UK: Pearson Education

[2] V. Wang (2009) "E-learning Applications for Career and Technical Education". USA:IGI Global.

[3] E. Turban, E. McLean, and J. Wetherbe. (1999) "Information technology for management". New York: Wiley.

[4] R.C. Clark and R.E. Mayer (2003)"E-learning and the Science of Instruction". USA: Pfeiffer.

[5] K. Smart and J. Cappel (2006) "Students' Perception of Online Learning: A Comparative Study". Journal of Information Technology Education, 5.

[6] A. Thatcher and A. DeLaCour (2003) "Small group decisionmaking in face-to-face and computer mediated environments: the role of personality". Behaviour \& Information Technology 22, (3), 203-218. http://dx.doi.org/10.1080/0144929031000117071

[7] R. Sharpe and G. Benfield (2005) "The Student Experience of Elearning in Higher Education: A Review of the Literature". Brookes eJournal of Learning and Teaching 1, (1).

[8] J. Johnston, J. Killon, and J. Oomen (2005) "Student Satisfaction in the Virtual Classroom". Internet Journal of Allied Health Sciences and Practice 3, (2) 540-580.

[9] A. Seyal, M. Rahman, and M. Rahim (2002) "Determinants of academic use of the Internet: A structural equation model". Behaviour \& Information Technology, 21(1), 71-86. http://dx.doi.org/10.1080/01449290210123354

[10] C. Keller and L. Cernerud (2002) "Students' Perception of Elearning in University Education". Journal of Educational Media 27, (1-2).

[11] J. Peltier, J. Schibrowsky, and W. Drago (2007) "The Interdependence of the Factors Influencing the Perceived Quality of the Online Learning Experience: A Causal Model". Journal of Marketing Education 29, 140-153. http://dx.doi.org/10.1177/ 0273475307302016

[12] L. Jump and R. Jump (2006) "Learning academic skills online: Students perception of the learning process". Proceeding of the
First International LAMS Conference 2006: Designing the Future of Learning.

[13] G. Karns (2005) "An Update of Marketing Student Perceptions of Learning Activities: Structure, Preferences, and Effectiveness". Journal of Marketing Education 27, 163-171. http://dx.doi.org/10.1177/0273475305276641

[14] N. Buzzetto-Morre (2008) 'Students' Perception of Various ELearning Tools". Interdisciplinary Journal of E-Learning and Learning Objects (4).

[15] S. Palmer and D. Holt (2009) "Students' Perceptions of the Value of the Elements of an Online Learning Environment". Interactive Learning Environments.

[16] M.R. Martinez-Torres, S.L. Toral Marin, F. Barrero Garcia, S. Gallardo Vazquez, M. Arias Oliva and M. Torres (2008) "A technological acceptance of e-learning tools used in practical and laboratory teaching, according to the European higher education area". Behaviour \& Information Technology 27, (6) 495-505 http://dx.doi.org/10.1080/01449290600958965

[17] S.S. Al-Gahtani and M. King (1999) Attitudes, satisfaction and usage: factors contributing to each in the acceptance of information technology. Behaviour \& Information Technology, 18:4, pp. 277-297. http://dx.doi.org/10.1080/014492999119020

[18] E.M. Rogers (1995) "Diffusion of Innovations". New York: The Free Press.

[19] F.D. Davis (1986) "A technology acceptance model for empirically testing new end-user acceptance of information technology". Massachusetts Institute of Technology, Boston: Unpublished Doctoral Dissertation.

[20] W. Ralph (1991) "The art f computer technical support". California: Peachipt Press.

[21] O. Williams (2002) "The learning Web: the development, implementation, and evaluation of Internet-based undergraduate materials for the teaching of key skills". Active Learning in Higher Education 3, (1) 40-53. http://dx.doi.org/10.1177/146978740 2003001004

[22] M. Igbaria, T. Gamers, and G.B. Davis (1990) "Testing the determinants of micro-computer usage via a structural equation model". Journal of Management Information Systems 11, (4) 87-114.

[23] H.M. Selim (2003) "An empirical investigation of student acceptance of course websites". Computers \& Education 40, 343360. http://dx.doi.org/10.1016/S0360-1315(02)00142-2

[24] R. Piekkari and C. Welch (2004) "Handbook of Qualitative Research Methods for International Business". Edward Elgar Publishing. http://dx.doi.org/10.4337/9781781954331

[25] D. Morgan (1997) "Focus groups as qualitative research". UK: Sage Publications.

[26] G. Krueger, (1995) "Definition of Strategy". Cited in The Last Word: Strategy: What the Heck Is It?, Journal of Business Strategy $16,(3) 64$.

[27] M. Sunders, A. Thornhill, and P. Lewis (2003) "Research methods for Business Students". Prentice Hall.

[28] Y.J. Joo, K.Y. Lim, and E.K. Kim (2011) "Online university students' satisfaction and persistence: Examining perceived level of presence, usefulness and ease of use as predictors in a structural model". Journal of Computers \& Education 3rd March.

[29] E.W.T. Ngai, J.K.L. Poon, and Y.H.C. Chan (2007) "Empirical examination of the adoption of WebCT using TAM". Computers \& Education, 48, (2), 250-267. http://dx.doi.org/10.1016/ j.compedu.2004.11.007

\section{AUTHORS}

M.M. Abbad is with Hashemite University, Zarqa, Jordan.

F.N. Jaber is with Arab Open University, Amman, Jordan.

Submitted 11 December 2013. Published as resubmitted by the authors 14 June 2014. 